\title{
Feeding rates and prey: predator size ratios of the nauplii and adult females of the marine cyclopoid copepod Oithona davisae
}

\author{
Enric Saiz, ${ }^{1,{ }^{*}}$ Kaiene Griffell, ${ }^{1}$ Albert Calbet, ${ }^{1}$ and Stamatina Isari 1,2 \\ ${ }^{1}$ Institut de Ciències del Mar, Consejo Superior de Investigaciones Científicas, Barcelona, Catalonia, Spain \\ ${ }^{2}$ Institute of Oceanography, Hellenic Centre for Marine Research, Anavyssos, Athens, Greece
}

\begin{abstract}
We studied the feeding behavior of the nauplii and adult females of the marine cyclopoid copepod Oithona davisae in the laboratory. Functional response experiments showed that $O$. davisae can feed on a broad size range of prey but that high clearance rates only occur in a narrow prey size range. Neither the nauplii nor the females were able to feed on Nannochloropsis oculata $(2.5 \mu \mathrm{m})$, but $>4 \mu \mathrm{m}$ prey were ingested. The highest clearance rates occurred when the nauplii and females were offered the dinoflagellate Oxyrrhis marina and the ciliate Strombidium sulcatum, respectively. O. davisae females preyed on Acartia grani nauplii but not on nauplii of their own species. Optimal prey: predator size ratios were similar for the nauplii and the females $(\sim 10 \%$ of the predator's body length) and were higher than those reported for suspension-feeding calanoid copepods (2-6\%). The finding that the nauplii and females of $O$. davisae feed on relatively larger prey appears to be a consequence of their strict ambush-feeding behavior, which constrains feeding activity to prey large enough to create hydromechanical signals above the detection threshold. Very high weight-specific ingestion rates $\left(>150 \% \mathrm{~d}^{-1}\right)$ were obtained when $O$. davisae fed on relatively large prey. Such high daily rations are much higher than those that can be calculated indirectly from egg production. Size measurements of the mouth of $O$. davisae females indicate that those prey resulting in extreme feeding rates were too large to be swallowed completely and suggest the presence of sloppy feeding in Oithona.
\end{abstract}

Despite the numerical dominance of the genus of marine copepods Oithona in most of the oceans (Gallienne and Robins 2001) and the expected important role of Oithona in the pelagic system (Paffenhöfer 1993; Nielsen and Sabatini 1996), many basic aspects of the biology and ecology of the genus are still poorly known. This lack of information limits our capacity to understand the function of Oithona in marine food webs. We know that their strict ambush-feeding behavior (Svensen and Kiørboe 2000; Paffenhöfer and Mazzocchi 2002), which reduces the encounter rate with potential prey, is associated with feeding and metabolic rates comparatively lower than those of calanoid copepods (Castellani et al. 2005b; Saiz and Calbet 2007). Moreover, the few available data obtained in the laboratory under controlled conditions also suggest that the adult females of Oithona may satiate at low food concentrations (50-100 $\mu \mathrm{g} \mathrm{C} \mathrm{L}^{-1}$; Lampitt and Gamble 1982; Saiz et al. 2003; Zamora-Terol and Saiz 2013).

Knowledge of the feeding behavior of Oithona is still deficient in comparison with that of calanoid copepods, and this limited information has resulted in contradictory observations in the literature. In most field studies on the feeding of this genus, ciliates and dinoflagellates have emerged as the main components of its natural diet (Atkinson 1995; Nakamura and Turner 1997; Broglio et al. 2004), whereas diatoms and nanoflagellates may occasionally appear in the diet, often as minor contributors (Castellani et al. 2005a, 2008; Atienza et al. 2006). However, Calbet et al. (2000), in waters off Kaneohe Bay (Hawaii), reported high feeding rates of Oithona nana and Oithona simplex (up to $\sim 55 \%$ body $\mathrm{C} \mathrm{d}^{-1}$ ) on $2-5 \mu \mathrm{m}$ flagellates. The pioneering work of Lampitt and Gamble (1982) on O. nana in the laboratory also reported

\footnotetext{
*Corresponding author: enric@icm.csic.es
}

ingestion of nanoflagellates and diatoms, whereas Uchima and Hirano (1986) reported only ingestion of motile prey by Oithona davisae and the absence of feeding on diatoms. We think that some of the abovementioned disagreement might be, in part, a consequence of likely presence of trophic cascade effects in the feeding experiments with natural prey assemblages, which may mask the actual diet of Oithona (Nejstgaard et al. 2001; Saiz and Calbet 2011). Such effects would be particularly important in this genus, given that its highest clearance rates have been found for the top predators of the microbial communities (i.e., ciliates and heterotrophic dinoflagellates).

However, the few laboratory feeding experiments on the genus reported in the literature are difficult to compare, as they focused on different conspecifics and a small variety of prey types. This lack of knowledge on the genus is even more pronounced if the juvenile stages (nauplii) are considered, as most of the studies on copepod vital rates typically focus on the adult or late copepodite stages. The few available studies on Oithona nauplii assessing their feeding rates and functional response to food availability in the laboratory (Henriksen et al. 2007; Almeda et al. 2010a) have only considered two dinoflagellates and a diatom as potential prey.

The aim of the current study is, therefore, to determine the feeding functional response of the nauplii and adult females of the ambush cyclopoid copepod $O$. davisae. We have assessed the feeding rates of the species and its prey size spectrum using a variety of prey (algae, ciliates, and copepod nauplii). To our knowledge, a similar approach has only been pursued once in marine copepods, in the study of Berggreen et al. (1988), where ontogenetic changes in the feeding rates of the calanoid copepod Acartia tonsa were studied at saturating concentrations under a variety of 
Table 1. List of the feeding functional response experiments conducted with nauplii of Oithona davisae. For each prey type, size

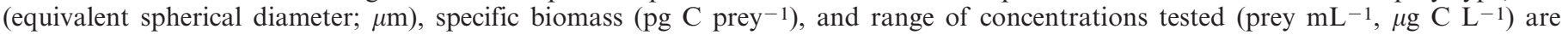
provided. Total body length $(\mu \mathrm{m})$, specific biomass $\left(\mu \mathrm{g} \mathrm{C}\right.$ ind. $\left.{ }^{-1}\right)$, and concentration of the nauplii in the incubations (ind. bottle $\left.{ }^{-1}\right)$ are given.

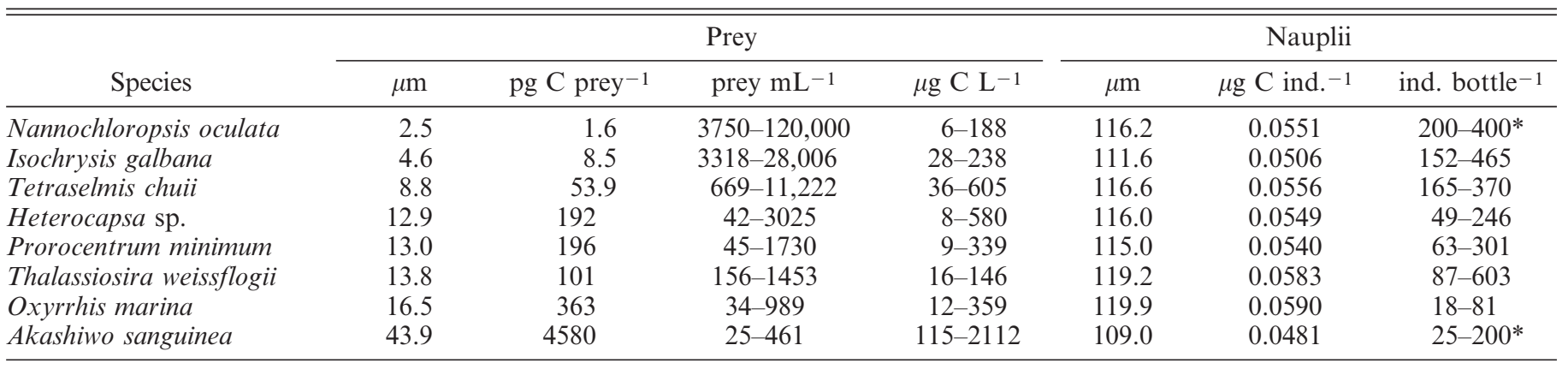

* Nominal concentrations.

mono-diets. A recent study by Vogt et al. (2013) also addressed the feeding behavior of the nauplii and adults of $O$. davisae, but it did not assess the feeding functional response on a variety of prey types. Our study provides evidence that the prey spectrum of $O$. davisae is constrained by the ambush-feeding behavior of the species and that both the nauplii and adults show similar optimal prey: predator size ratios that are larger than those of suspension-feeding calanoid copepods. Finally, we examine the possibility of sloppy feeding in Oithona to explain some of the high daily rations observed in our experiments.

\section{Methods}

We conducted feeding experiments with adult females and naupliar stages of the marine copepod $O$. davisae. Copepods were obtained from our continuous culture, running at the Institut de Ciències del Mar since 2000, which is grown in 20 liter methacrylate cylinders at $18 \pm$ $1{ }^{\circ} \mathrm{C}$ with a 12:12 light: dark (LD) light cycle and fed with the heterotrophic dinoflagellate Oxyrrhis marina. Cohorts of nauplii for the experiments were obtained by the protocol described in Henriksen et al. (2007). Briefly, egg-bearing females were collected with a $130 \mu \mathrm{m}$ sieve and transferred to a 10-15 liter container with filtered seawater and a small amount of Ox. marina as food. After $\sim 24 \mathrm{~h}$, the water containing the newly hatched nauplii was gently siphoned out of the tank through a $60 \mu \mathrm{m}$ sieve, which retained only the females, and transferred into a new container where the nauplii were left growing for $3 \mathrm{~d}$ until stages NII-NIII. Females for experiments were also obtained from artificial cohorts raised to adulthood; only adult females $<2$ weeks old were used in the feeding experiments.

Tables 1, 2 provide a list of the prey types and sizes used in the experiments as well as the range of prey concentrations. Algae for the experiments were grown in batch cultures on $\mathrm{f} / 2$ medium at $18 \pm 1{ }^{\circ} \mathrm{C}$ and at $12: 12 \mathrm{LD}$. Algal cultures were diluted daily or every $2-3 \mathrm{~d}$, depending on their growth rate, to keep them in the exponential phase. The heterotrophic dinoflagellate $O x$. marina was fed the

Table 2. List of the feeding experiments conducted with adult females of Oithona davisae. For each prey type, size (equivalent spherical diameter; $\mu \mathrm{m}$ ), specific biomass (pg C prey ${ }^{-1}$ ), and range of concentrations tested (prey $\mathrm{mL}^{-1}, \mu \mathrm{g} \mathrm{C} \mathrm{L}^{-1}$ ) are provided. Prosome length $(\mu \mathrm{m})$, specific biomass $\left(\mu \mathrm{g} \mathrm{C}\right.$ ind. $\left.{ }^{-1}\right)$, and concentration of females in the incubations (ind. bottle $\left.{ }^{-1}\right)$ are given. Func. Resp., functional response experiments. Fmax, experiments conducted at low prey availability to estimate maximum clearance rates.

\begin{tabular}{|c|c|c|c|c|c|c|c|c|}
\hline \multirow{2}{*}{$\begin{array}{l}\text { Experiment } \\
\text { type }\end{array}$} & \multirow[b]{2}{*}{ Species } & \multicolumn{4}{|c|}{ Prey } & \multicolumn{3}{|c|}{ Adults } \\
\hline & & $\mu \mathrm{m}$ & pg C prey $^{-1}$ & prey $\mathrm{mL}^{-1}$ & $\mu \mathrm{g} \mathrm{C} \mathrm{L}^{-1}$ & $\mu \mathrm{m}$ & $\mu \mathrm{g} \mathrm{C}$ ind. ${ }^{-1}$ & ind. bottle ${ }^{-1}$ \\
\hline \multirow[t]{11}{*}{ Func. Resp. } & Nannochloropsis oculata & 2.5 & 1.6 & $3750-120,000$ & $6-188$ & 299.2 & 0.349 & $25-35^{*}$ \\
\hline & Isochrysis galbana & 4.2 & 6.8 & $4654-38,456$ & $32-260$ & 320.9 & 0.390 & $28-41$ \\
\hline & Tetraselmis chuii & 8.3 & 45.4 & $2131-23,546$ & $97-1068$ & 317.7 & 0.384 & $29-47$ \\
\hline & Heterocapsa sp. & 12.4 & 171 & $487-8799$ & $83-1508$ & 309.4 & 0.368 & $18-42$ \\
\hline & Prorocentrum minimum & 12.4 & 172 & $606-6378$ & $104-1096$ & 313.0 & 0.375 & $16-35$ \\
\hline & Thalassiosira weissflogii & 13.7 & 100 & $156-4140$ & $16-412$ & 295.4 & 0.342 & $25-55$ \\
\hline & Oxyrrhis marina & 18.1 & 463 & $28-1337$ & $13-618$ & 292.2 & 0.336 & $6-21$ \\
\hline & Strombidium sulcatum & 29.0 & 1833 & $11-488$ & 19-894 & 300.3 & 0.351 & $5-17$ \\
\hline & Akashiwo sanguinea & 42.9 & 4311 & $11-697$ & $46-3003$ & 322.2 & 0.393 & $14-40$ \\
\hline & Oithona davisae nauplii & 66.9 & 39,881 & $2.2-7.3$ & 89-290 & 295.7 & 0.342 & $29-45$ \\
\hline & Acartia grani nauplii & 84.3 & 27,390 & $0.5-9.0$ & $14-247$ & 309.7 & 0.369 & $25-34$ \\
\hline \multirow[t]{3}{*}{ Fmax } & Scrippsiella trochoidea & 21.8 & 746 & $15-77$ & $11-58$ & 319.9 & 0.389 & $12-19$ \\
\hline & Prorocentrum micans & 27.0 & 1296 & $31-66$ & $40-85$ & 317.4 & 0.383 & $7-10$ \\
\hline & Strombidium sulcatum & 30.0 & 2026 & $12-59$ & $23-119$ & 320.5 & 0.390 & $4-10$ \\
\hline
\end{tabular}

\footnotetext{
* Nominal concentrations.
} 
alga Rhodomonas baltica. The ciliate Strombidium sulcatum was grown on bacteria in a wheat-enriched medium. Copepod nauplii (as prey) were obtained similarly to the abovementioned procedure in the case of $O$. davisae or directly by hatching spawned eggs from our culture of the calanoid Acartia grani.

Functional response experiments were conducted in 65 $75 \mathrm{~mL}$ plastic cell-culture flasks. Prey suspensions were prepared at the highest desired concentration and were then serially diluted with $0.2 \mu \mathrm{m}$ filtered seawater into the six or seven concentrations to be tested in the functional response. To further assess the relationships between maximum clearance rates and prey size, additional experiments with extra prey were conducted, but only at low prey concentrations (Fmax experiments; Table 2). We added $5 \mathrm{~mL}$ of $\mathrm{f} / 2$ medium per liter of suspension in all cases to reduce any differential effect on algal growth of copepod excretion during incubation. We typically prepared five bottles for each concentration: one was used as the initial bottle and was sampled at the beginning of the experiment to determine the initial concentrations; two bottles served as controls to monitor the changes in the prey concentration during the incubation; the remaining two bottles, containing added predators, served as experimental bottles. The nauplii offered as prey were concentrated from the cohort stock and counted in triplicate. Aliquots of different volumes were then withdrawn to achieve the desired concentration of nauplii in the bottles. The number of predators (either adult female or NII-NIII of $O$. davisae) added to the experimental bottles varied depending on prey type and concentration and typically increased with prey concentration (Tables 1, 2). For those prey that we expected beforehand not to be consumed at high rates, the abundance of predators was increased to enhance the probability of detecting the presence of feeding even if it occurred at low rates. Adult females were individually pipetted into the experimental bottles. For nauplii, the suspensions were prepared and counted, and aliquots containing the desired concentration of nauplii were then added to each experimental bottle. Other experimental procedures were similar to the ones described above for the adult females.

After the predators were added, the bottles were filled to the top with the prey suspensions, the lid was covered with plastic film to ensure no air bubbles were present, and the bottles were capped. The initial bottles were sacrificed at the beginning of the experiment and preserved in acetic Lugol's solution ( $2 \%$ final concentration). The remaining bottles were placed on a rotating wheel at 0.2 revolutions $\min ^{-1}$. After $24 \mathrm{~h}$, the bottles were taken off the wheel, the copepods were checked visually to verify that they were alive, and the contents of the bottle were then preserved in acetic Lugol's solution ( $2 \%$ final concentration). The Lugol's samples were analyzed under an inverted microscope $(100 \times$ or $200 \times)$ using either Sedgwick-Rafter or differently sized settling chambers. The samples were intended to achieve a minimum of 300-400 cells counted per chamber. Triplicate Sedgwick-Rafter chambers were typically set for the smallest and more abundant prey. For the relatively larger and less abundant prey, different sample volumes were settled, and the whole, or a certain fraction, of the settling chamber area was processed. In the case of Tetraselmis chuii as prey, however, as the preservation with Lugol's solution resulted in the formation of aggregates that made the counting difficult, the initial and final concentrations had to be measured in fresh samples with a Coulter Multisizer III particle counter. For Nannochloropsis oculata, due to their small size and high concentration, cell concentrations were estimated from chlorophyll $a$ analysis rather than from Lugol's counts. Aliquots of $5 \mathrm{~mL}$ from each bottle were filtered onto $25 \mathrm{~mm}$ Whatman GF/F filters, frozen, and later extracted overnight in darkness at $4^{\circ} \mathrm{C}$ in $90 \%$ acetone. Chlorophyll $a$ was determined with a Turner Designs fluorometer after acidification. Extra initial samples were preserved in Lugol's solution to allow for the conversion of chlorophyll $a$ concentration to cell concentration.

The carbon content of the prey was estimated from the size using the equations of Menden-Deuer et al. (2001) for dinoflagellates, diatoms, and protists and those of Putt and Stoecker (1989) for ciliates; ciliate abundance was corrected for Lugol fixation losses according to Broglio et al. (2004). The equivalent spherical diameter (ESD) of the algae and protozoans was determined at the beginning of the incubations from stocks using a Coulter Multisizer III particle counter, except for $N$. oculata, which was measured under an inverted microscope at $400 \times$.

The abundance of copepods in the incubations was determined using a stereomicroscope. Digital pictures of the females and nauplii were taken under the stereomicroscope and the inverted microscope, respectively, and the female prosome length and nauplii body length were measured with ImageJ software (http://imagej.nih.gov/ij/). The carbon content was estimated with the carbon-length relationship of Almeda et al. (2010b) for this species. The nauplii of $A$. grani were treated similarly but converted into carbon values using the equation of Berggreen et al. (1988) for A. tonsa nauplii.

The equations of Frost (1972) were used to compute clearance rates, average food concentrations, and ingestion rates. Prior to the calculations, significant differences $(p<$ 0.05 ) in prey growth rate between control and experimental bottles were tested with ANOVA tests for the whole functional response, with post hoc contrasts for each prey concentration if necessary; $t$-tests were conducted for the non-functional response incubations. The functional response data were fitted to exponential or power functions (clearance rates) or to linear or asymptotic (MichaelisMenten) functions (ingestion rates) if possible. As on occasion fits were not possible or provided unrealistic values of maximum vital rates that hindered a comparison among prey, we opted to estimate the maximum clearance rate for each prey as the maximum value among the average clearance rates at the three lowest food concentrations tested, whereas the maximum ingestion rate was estimated as the maximum of the average ingestion rates at the three highest food concentrations tested.

\section{Results}

Figure 1 shows the clearance and ingestion rates of $O$. davisae nauplii for those prey that elicited significant grazing. Nauplii of $O$. davisae did not feed significantly on N. oculata, Prorocentrum minimum, or Akashiwo sanguinea. For the remaining prey, clearance rates decreased with food 


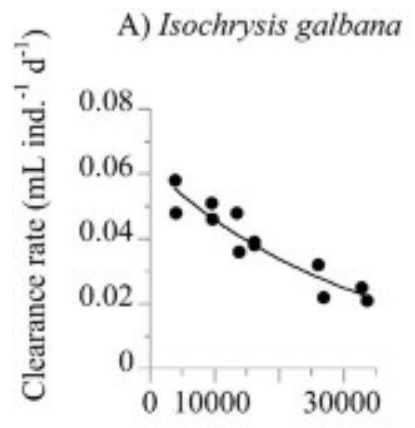

B) Tetraselmis chuii

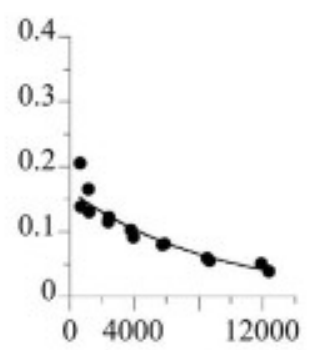

Prey concentration (cells $\mathrm{mL}^{-1}$ )

Prey biomass $\left(\mu \mathrm{g} \mathrm{C} \mathrm{mL}^{-1}\right)$

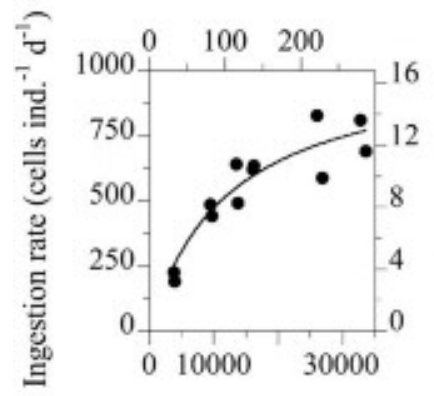

C) Heterocapsa sp.

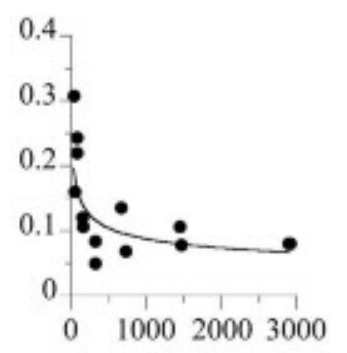

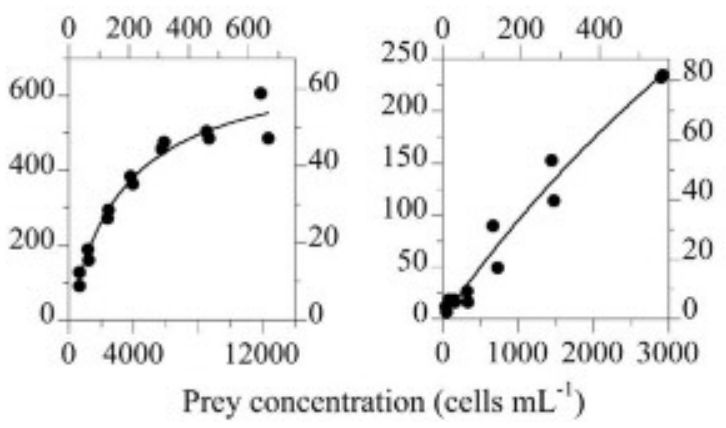

D) Oxyrrhis marina

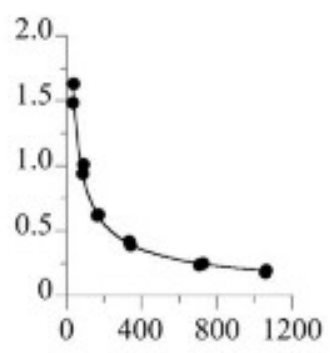

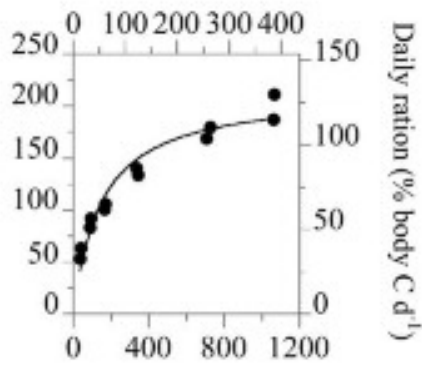

Fig. 1. Clearance $\left(F, \mathrm{~mL}\right.$ ind..$\left.^{-1} \mathrm{~d}^{-1}\right)$ and ingestion rates ( $I$, per capita and weight-specific, respectively cells ind.$^{-1} \mathrm{~d}^{-1}$ and $\%$ body $\left.\mathrm{C}^{-1}\right)$ of nauplii of Oithona davisae as a function of prey availability $\left(C\right.$, cells $\left.\mathrm{mL}^{-1}\right)$ in the functional response experiments. Equations of the fits given in the legend. (A) Isochrysis galbana $\left(F=0.062 \times \mathrm{e}^{(-0.00003 \times C)}, R^{2}=0.87 ; I=(1052 \times C) /(12,385+C), R^{2}=0.86\right),(\mathrm{B})$ Tetraselmis chuii $\left(F=0.16 \times \mathrm{e}^{(-0.00011 \times C)}, R^{2}=0.87 ; I=(706 \times C) /(3437+C), R^{2}=0.97\right),(\mathrm{C})$ Heterocapsa $\mathrm{sp} .\left(F=0.50 \times C^{-0.25}, R^{2}=\right.$ $\left.0.61 ; I=(1053 \times C) /(10,184+C), R^{2}=0.97\right)$, (D) Oxyrrhis marina $\left(F=16.4 \times C^{-0.64}, R^{2}=0.99 ; I=(214 \times C) /(149+C), R^{2}=0.94\right)$.

concentration and depended on food type. The highest nauplii clearance rates were observed when feeding on Ox. marina (range of clearance rates at the various food concentrations tested: $1.63-0.18 \mathrm{~mL}$ individual [ind. ${ }^{-1} \mathrm{~d}^{-1}$ ), and the lowest significant nauplii clearance rates were observed when feeding on Isochrysis galbana (range: $\sim 0.06-0.02 \mathrm{~mL}$ ind. ${ }^{-1} \mathrm{~d}^{-1}$; Fig. 1). Per capita nauplii ingestion rates increased to $600-800$ cells ind. ${ }^{-1} \mathrm{~d}^{-1}$ when feeding on I. galbana and T. chuii and reached values up to $\sim 200$ cells ind. ${ }^{-1} \mathrm{~d}^{-1}$ in the case of Heterocapsa sp. and Ox. marina (Fig. 1). The ingestion rates of nauplii increased with increasing food concentrations and reached a certain degree of satiation at the upper range of food concentrations tested, except when fed Heterocapsa sp. (Fig. 1). The maximum daily rations of nauplii (weightspecific ingestion rates as percentage) increased with increasing prey size, reaching as much as $122 \%$ body $\mathrm{C} \mathrm{d}^{-1}$ when feeding on $O x$. marina (Fig. 1).

Oithona adult females ate detectable amounts of all prey offered except $N$. oculata and O. davisae nauplii. Overall, female clearance rates declined as prey concentration increased (Fig. 2). For the ingested prey types, the highest female clearance rates were observed when feeding on the ciliate $S$. sulcatum $\left(9.6-11.7 \mathrm{~mL}\right.$ ind. $\left.{ }^{-1} \mathrm{~d}^{-1}\right)$ and $O x$. marina $\left(4.6 \mathrm{~mL}\right.$ ind. $\left.{ }^{-1} \mathrm{~d}^{-1}\right)$. For the remaining prey, the clearance rates were below $1 \mathrm{~mL}$ ind. ${ }^{-1} \mathrm{~d}^{-1}$ on most occasions (Fig. 2). Clear satiation responses were achieved for certain prey types (e.g., T. chuii, S. sulcatum, and Ak. sanguinea); for other prey types, however, satiation was not achieved
(Fig. 2). In the case of I. galbana (Fig. 2), female ingestion rates decreased at the greatest food concentration, most likely as a consequence of insufficient grazing pressure in the bottles due to the combined effect of extremely low clearance rates and the high cell concentrations.

The maximum cell ingestion rates of females were up to $\sim 5000$ cells ind. ${ }^{-1} \mathrm{~d}^{-1}$ when feeding on I. galbana and up to $\sim 3000-4000$ cells ind. ${ }^{-1} \mathrm{~d}^{-1}$ when feeding on $T$. chuii and Heterocapsa sp. The maximum female ingestion rates decreased as prey size increased, reaching values of 96 and 2.9 prey ind. ${ }^{-1} \mathrm{~d}^{-1}$ for the larger prey, Ak. sanguinea and A. grani nauplii, respectively (Fig. 2). The maximum daily rations of females were comparatively low when feeding on I. galbana, T. chuii, and A. grani nauplii (Fig. 2), whereas the overall values for the other prey were $>100 \% \mathrm{C} \mathrm{d}^{-1}$, reaching $>150 \% \mathrm{C} \mathrm{d}^{-1}$ in certain cases (i.e., Heterocapsa sp., Ox. marina, and S. sulcatum; Fig. 2).

The experiments conducted with the diatom Thalassiosira weissflogii showed significant $(p<0.05)$ ingestion rates only at low prey concentrations $(<1916$ and $<870$ cells $\mathrm{mL}^{-1}$ for nauplii and adults, respectively). For nauplii, the clearance rates at diatom concentrations of 202 and 430 cells $\mathrm{mL}^{-1}$ were 0.15 and $0.03 \mathrm{~mL}$ ind. ${ }^{-1} \mathrm{~d}^{-1}$, respectively, representing daily rations of $5.1 \%$ and $2.5 \%$ body $\mathrm{C} \mathrm{d}^{-1}$, respectively (Table 3 ). The adult females showed moderately higher clearance rates on the diatom $(0.90-0.24 \mathrm{~mL}$ ind. ${ }^{-1} \mathrm{~d}^{-1}$ ), but the daily rations were similar to those of the nauplii (4.9-5.8\% body $\mathrm{C} \mathrm{d}^{-1}$; Table 3 ). 
A) Isochrysis galbana
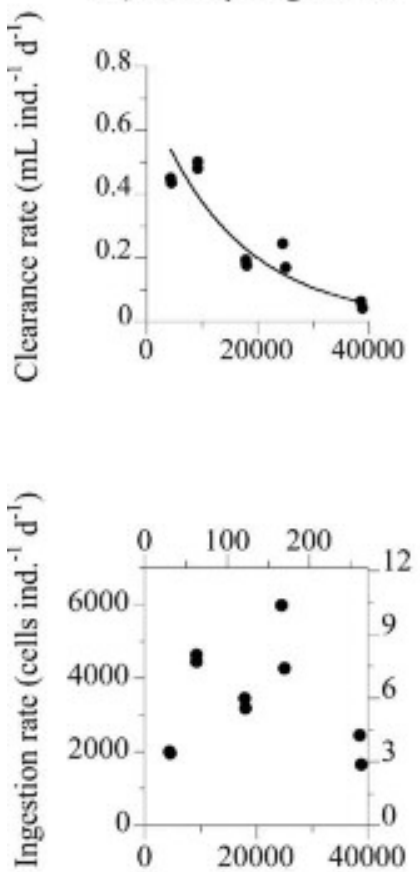

E) Oxyrrhis marina
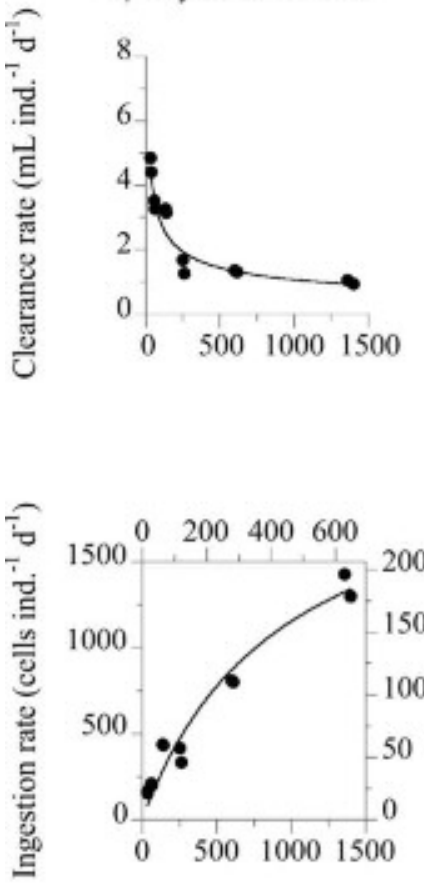

B) Tetraselmis chuii

C) Heterocapsa sp.

D) Prorocentrum minimum
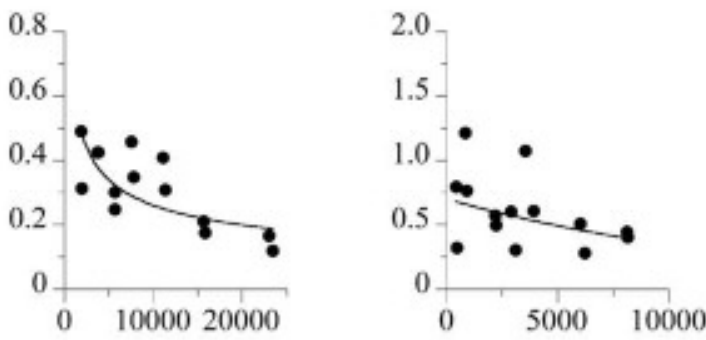

Food concentration (prey $\mathrm{mL}^{-1}$ )

Prey biomass ( $\mu \mathrm{g} \mathrm{C} \mathrm{mL}^{-1}$ )
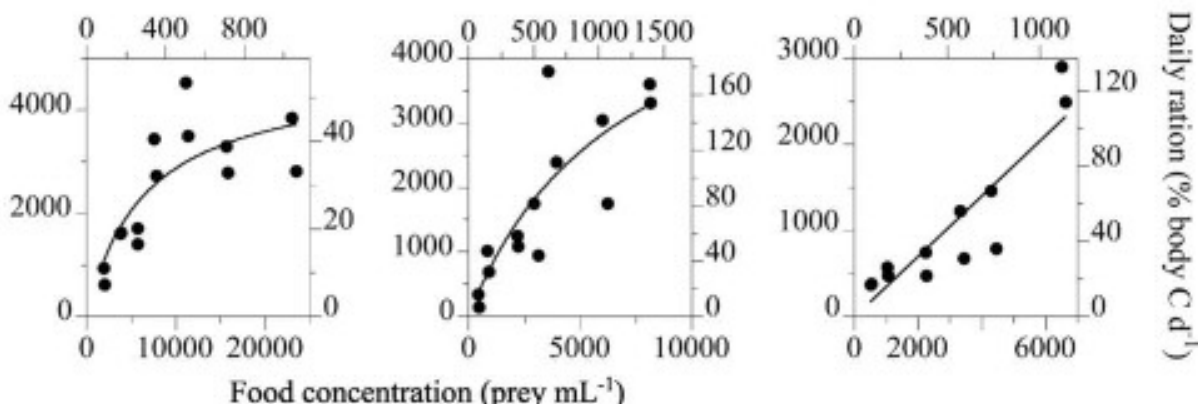

Food concentration (prey $\mathrm{mL}^{-1}$ )

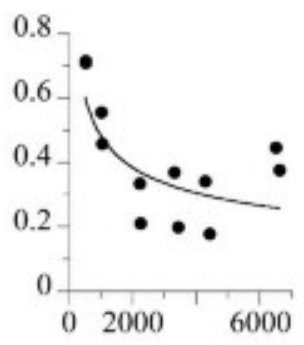

G) Akashiwo sanguinea

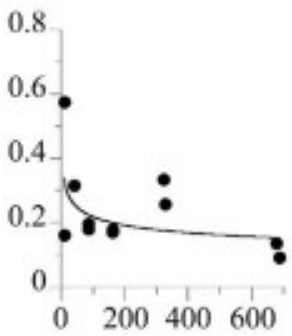

Food concentration (prey $\mathrm{mL}^{-1}$ )

Prey biomass ( $\mu \mathrm{g} \mathrm{C} \mathrm{mL}^{-1}$ )

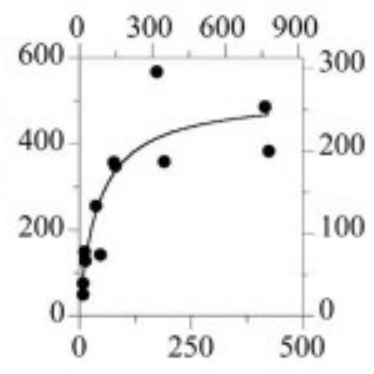

F) Strombidium sulcatum

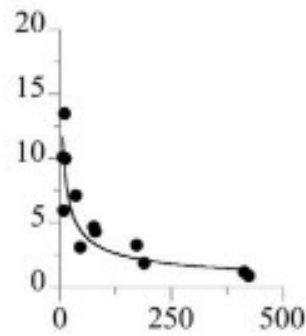

H) Acartia grani nauplii

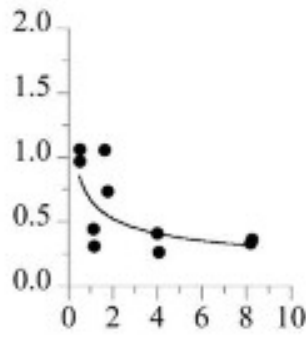

Food concentration (prey $\mathrm{mL}^{-1}$ )

Fig. 2. Clearance $\left(F, \mathrm{~mL}\right.$ ind..$\left.^{-1} \mathrm{~d}^{-1}\right)$ and ingestion rates $\left(I\right.$, per capita and weight-specific, respectively prey ind..$^{-1} \mathrm{~d}^{-1}$ and $\%$ body $\left.\mathrm{C}^{-1}\right)$ of adult females of Oithona davisae as a function of food availability $\left(C\right.$, prey $\left.\mathrm{mL}^{-1}\right)$ in the functional response experiments. Equations of the fits given in the legend. (A) Isochrysis galbana $\left(F=0.72 \times \mathrm{e}^{(-0.00006 \times C)}, R^{2}=0.83\right)$, (B) Tetraselmis chuii $(F=9.17 \times$ $\left.C^{-0.39}, R^{2}=0.44 ; I=(4767 \times C) /(6643+C), R^{2}=0.68\right),(C)$ Heterocapsa $\mathrm{sp} .\left(F=0.70 \times \mathrm{e}^{(-0.00007 \times C)}, R^{2}=0.19 ; I=(6058 \times C) /(6888\right.$ $\left.+C), R^{2}=0.71\right)$, (D) Prorocentrum minimum $\left(F=4.84 \times C^{-0.33}, R^{2}=0.64 ; I=-18.3+0.35 \times C, R^{2}=0.81\right)$, (E) Oxyrrhis marina $(F=$ $\left.21.2 \times C^{-0.43}, R^{2}=0.93 ; I=(2245 \times C) /(953+C), R^{2}=0.94\right),(\mathrm{F})$ Strombidium sulcatum $\left(F=34.3 \times C^{-0.53}, R^{2}=0.70 ; I=(514 \times C) /\right.$ $\left.(43+C), R^{2}=0.82\right),(\mathrm{G})$ Akashiwo sanguinea $\left(F=0.52 \times C^{-0.19}, R^{2}=0.31 ; I=(135 \times C) /(345+C), R^{2}=0.77\right),(\mathrm{H})$ Acartia grani nauplii $\left(F=0.67 \times C^{-0.36}, R^{2}=0.49 ; I=(5.32 \times C) /(7.78+C), R^{2}=0.80\right)$. 
Table 3. Feeding rates of nauplii and adult females of Oithona davisae on the diatom Thalassiosira weissflogii. At higher prey concentrations (data not shown), the grazing pressure during incubation was not sufficiently high to produce significant grazing $(p<0.05$; see Results section). Average \pm standard error are provided.

\begin{tabular}{|c|c|c|c|c|c|}
\hline \multirow[b]{2}{*}{ Predator } & \multicolumn{2}{|c|}{ Prey concentration } & \multirow{2}{*}{$\begin{array}{l}\text { Clearance rate } \\
\left(\mathrm{mL} \text { ind. } .^{-1} \mathrm{~d}^{-1}\right)\end{array}$} & \multirow{2}{*}{$\begin{array}{l}\text { Ingestion rate } \\
\text { (cells ind. }{ }^{-1} \mathrm{~d}^{-1} \text { ) }\end{array}$} & \multirow{2}{*}{$\begin{array}{c}\text { Daily ration } \\
\left(\% \text { body } \mathrm{C} \mathrm{d}^{-1}\right)\end{array}$} \\
\hline & cells $\mathrm{mL}^{-1}$ & $\mu \mathrm{g} \mathrm{C} \mathrm{L}^{-1}$ & & & \\
\hline Nauplii & $202 \pm 2.1$ & $20 \pm 0.2$ & $0.15 \pm 0.028$ & $30 \pm 5.3$ & $5.1 \pm 0.92$ \\
\hline Nauplii & $430 \pm 3.7$ & $43 \pm 0.4$ & $0.03 \pm 0.007$ & $15 \pm 2.8$ & $2.5 \pm 0.48$ \\
\hline Females & $187 \pm 2.4$ & $19 \pm 0.2$ & $0.90 \pm 0.044$ & $167 \pm 6.0$ & $4.9 \pm 0.18$ \\
\hline Females & $410 \pm 8.2$ & $41 \pm 0.8$ & $0.42 \pm 0.110$ & $171 \pm 41.8$ & $5.0 \pm 1.22$ \\
\hline Females & $830 \pm 7.6$ & $83 \pm 0.8$ & $0.24 \pm 0.054$ & $198 \pm 42.7$ & $5.8 \pm 1.24$ \\
\hline
\end{tabular}

The prey size spectrum of the nauplii and the adult females of $O$. davisae, expressed in terms of the maximum clearance rate as a function of prey size, is shown in Fig. 3. The overall pattern shows low maximum clearance rates for most prey types independently of their size, on the order of $<0.25$ and $<2.2$ mL ind. ${ }^{-1} \mathrm{~d}^{-1}$ for nauplii and adults, respectively; a peak in clearance rates is observed for a few prey sizes $\left(1.6 \mathrm{~mL}\right.$ ind. ${ }^{-1} \mathrm{~d}^{-1}$ for the nauplii when offered the heterotrophic dinoflagellate $O x$. marina; up to $11.7 \mathrm{~mL}$ ind. ${ }^{-1} \mathrm{~d}^{-1}$ in the case of the females fed the ciliate $S$. sulcatum). In terms of maximum weight-specific ingestion rates, there was a positive relationship between maximum weight-specific ingestion rates of the nauplii and prey size (Fig. 3), reaching values up to $122 \%$ body $\mathrm{Cd}^{-1}$ when feeding on Ox. marina; the larger prey tested (Ak. sanguinea) was not ingested by the nauplii. Females showed a dome-shaped relationship between weight-specific ingestion rates and prey size (Fig. 3), with peak daily rations on the order of $188-242 \%$ body $\mathrm{C} \mathrm{d}^{-1}$ when feeding on Ox. marina and $S$. sulcatum and also relatively high values ( $161 \%$ body $\left.\mathrm{C} \mathrm{d}^{-1}\right)$ when feeding on Heterocapsa sp.

\section{Discussion}

Lower and upper prey size limits-Compared with calanoid copepods, which display a noteworthy variety of feeding behaviors and the capability to switch between them (Kiørboe et al. 1996), both the nauplii and adults of Oithona spp. are strict ambush feeders (Svensen and Kiørboe 2000; Henriksen et al. 2007). The inability to generate feeding currents in Oithona spp. substantially reduces the encounter rate with potential prey (Strickler

A) Oithona davisae nauplii

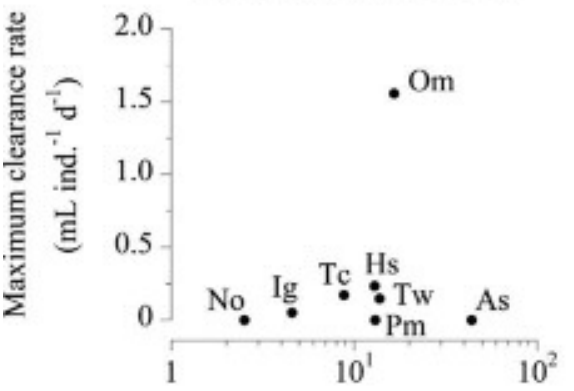

B) Oithona davisae females
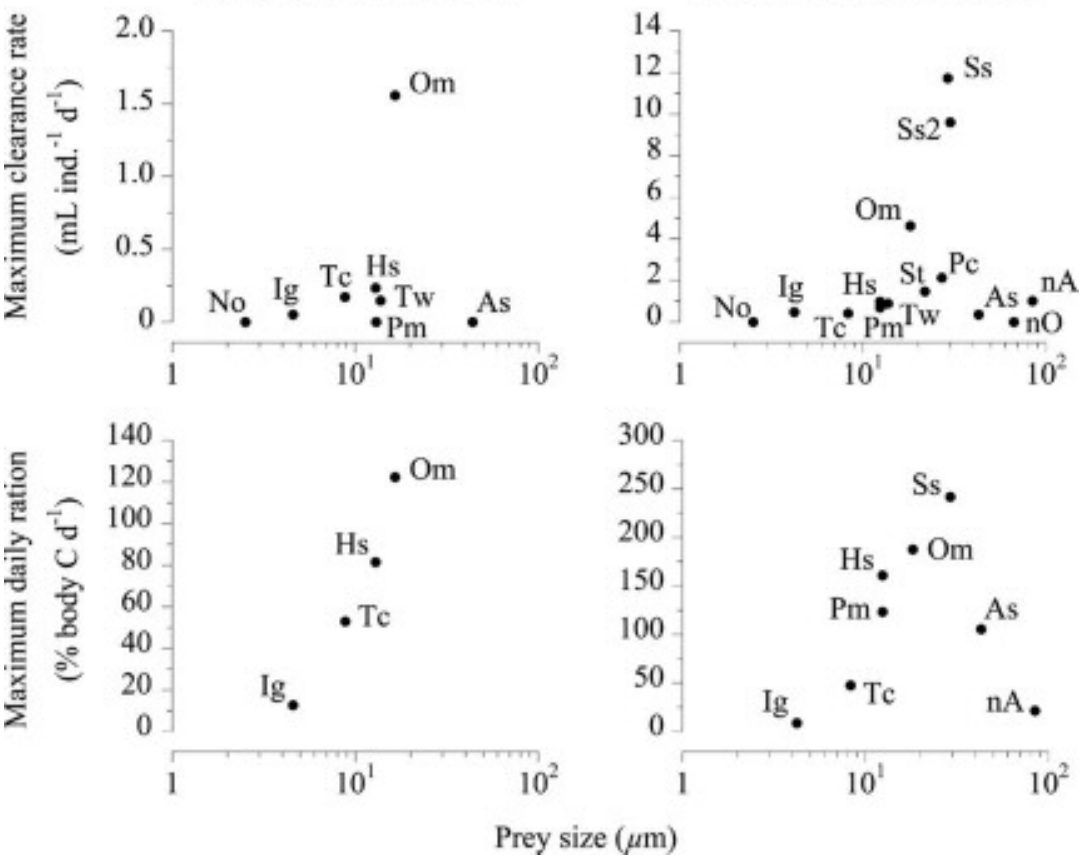

Fig. 3. Maximum clearance and weight-specific ingestion rates of (A) nauplii and (B) adult females of Oithona davisae as a function of prey size. No, Nannochloropsis oculata; Ig, Isochrysis galbana; Tc, Tetraselmis chuii; Hs, Heterocapsa sp.; Pm, Prorocentrum minimum; Tw, Thalassiosira weissflogii; Om, Oxyrrhis marina; St, Scrippsiella trochoidea from the Fmax experiments; Pc, Prorocentrum micans from the Fmax experiments; Ss, Strombidium sulcatum; Ss2, Strombidium sulcatum from the Fmax experiments; As, Akashiwo sanguinea; nO, Oithona davisae nauplii as prey; nA, Acartia grani nauplii as prey. 
1985) and constrains feeding primarily to motile prey or to rapidly sinking items that are perceived mechanosensorially (Kiørboe and Visser 1999).

It appears reasonable to assume that extremely small prey might not be detected efficiently by Oithona spp. because such small prey may not be able to generate a hydromechanical signal above the critical threshold for prey detection by the copepod. However, there has been disagreement in the literature on the capability of Oithona spp. to feed on extremely small prey. Although Atienza et al. (2006) and Calbet et al. (2000) did not observe significant feeding on picoplankton by Oithona spp., Castellani et al. (2008) reported occasional ingestion of $<2 \mu \mathrm{m}$ prey by Oithona similis. Other studies have reported consumption of $<5 \mu \mathrm{m}$ nanoflagellates in several Oithona species (Calbet et al. 2000; Castellani et al. 2005a; Atienza et al. 2006). In contrast, Nakamura and Turner (1997) did not observe feeding on $<8 \mu \mathrm{m}$ flagellates by $O$. similis. Natural-assemblage feeding incubations, however, are always prone to trophic cascades and may not provide reliable data at these lower trophic levels. The current study, in which cultured single suspensions were used, shows the inability of both the nauplii and the adult females of $O$. davisae to feed significantly on pico-sized algae ( $N$. oculata). In agreement with our results, Vogt et al. (2013), in laboratory experiments with prey monocultures, also found no evidence for the presence of picoplankton in the gut of Oithona nauplii. These observations contrast with the findings by Roff et al. (1995), who reported the presence of fluorescence-labeled bacteria in the gut of Oithona spp. nauplii. Whether or not picoplankton might be ingested or drunk on occasion, our study confirms that they must be cleared at negligible rates. We observed significant feeding of $O$. davisae on $>4 \mu \mathrm{m}$ nanoflagellates, similar to the observations of Lampitt and Gamble (1982) on $O$. nana and in agreement with several of the field experiments cited previously. We did not test the consumption of $<4 \mu \mathrm{m}$ nanoflagellates in our experiments, but it appears unlikely that it would occur at high rates, as $2.5 \mu \mathrm{m}$ prey were not ingested and $4 \mu \mathrm{m}$ prey (I. galbana) were ingested at low rates by $O$. davisae.

In the upper size range, $O$. davisae nauplii were unable to feed on the dinoflagellate Ak. sanguinea, most likely due to its comparatively large size (O. davisae nauplii: $109 \mu \mathrm{m}$ total body length; Ak. sanguinea: $44 \mu \mathrm{m} \mathrm{ESD).} \mathrm{Consistent}$ with the observations of Drits and Semenova (1984) in $O$. similis, the adult females of $O$. davisae did not feed on the nauplii of their own species, most likely due to the low motility displayed by Oithona nauplii (due to their ambushfeeding behavior; Henriksen et al. 2007), which reduced the encounter rates with potential predators. In contrast, $O$. davisae females did prey on A. grani nauplii, which are active swimmers (Henriksen et al. 2007). We cannot exclude the possibility that differences in escape ability between the nauplii of the two species may also help explain the lack of predation on $O$. davisae nauplii (Titelman 2001). The literature includes previous observations on the consumption of copepod nauplii by Oithona spp. Lampitt (1978) reported the ingestion of $A$. tonsa nauplii by $O$. nana at maximum rates ( 3.3 nauplii ind. ${ }^{-1} \mathrm{~d}^{-1}$ ) similar to the ones shown in our study by $O$. davisae females ( $\sim 3$ nauplii ind. ${ }^{-1}$ $\mathrm{d}^{-1}$ ). Lampitt and Gamble (1982) also reported the ingestion of Calanus nauplii by the same Oithona species, whereas Nakamura and Turner (1997) found that the nauplii of $A$. tonsa but not those of the harpacticoid Longipedia helgolandica were ingested by adults of $O$. similis. Moreover, McKinnon and Klumpp (1998) found high feeding rates on paracalanid nauplii (up to $\sim 12$ nauplii ind. ${ }^{-1} \mathrm{~d}^{-1}$ ) by a small tropical Oithona sp. Our maximum clearance rates on nauplii were relatively low compared with those reported by Lampitt (1978; $10.3 \mathrm{~mL}$ ind. $\left.{ }^{-1} \mathrm{~d}^{-1}\right)$ and those calculated from the data in McKinnon and Klumpp (1998; $80 \mathrm{~mL}$ ind. ${ }^{-1} \mathrm{~d}^{-1}$ ) for Oithona spp., most likely as a consequence of the higher nauplii concentrations used in our experiments. Although predation on copepod nauplii by Oithona is feasible, the extent to which this ingestion might be nutritionally relevant in the field at natural nauplii concentrations is questionable. Lampitt and Gamble (1982) estimated that in a Scottish loch, on a seasonal basis, the contribution of nauplii to the daily rations of $O$. nana was very small, occasionally reaching $10 \%$ of the requirements for respiration. In the Australian mangroves, McKinnon and Klumpp (1998) found that predation on nauplii by Oithona sp. might be sufficient, together with other prey, to explain the observed respiratory carbon requirements but not to explain the egg production rates displayed.

Grazing on nonmotile prey-The role of diatoms in the diet of Oithona spp. requires particular consideration. It is commonly accepted that Oithona spp. feed mainly on motile prey (Atkinson 1995; Paffenhöfer and Mazzocchi 2002) because nonmotile prey (including fecal pellets) would be poorly detected (Kiørboe and Visser 1999; Svensen and Kiørboe 2000; Reigstad et al. 2005). However, Lampitt and Gamble (1982) have reported significant ingestion (but at low rates) of the diatom Th. weissflogii by the copepod $O$. nana in the laboratory. In our experiments, we focused on motile prey, and only one nonmotile prey species (the non-chain-forming diatom $T h$. weissflogii) was tested. We did observe significant feeding by the nauplii and adults of $O$. davisae on Th. weissflogii, but we were able to detect it only at low food availability and high predator abundance; at higher prey concentrations, the low clearance rates prevented significant decreases in prey concentration during the incubations. Most likely, these low rates explain the lack of significant feeding on Th. weissflogii by $O$. davisae nauplii (same preypredator pair) in the feeding incubations reported by Henriksen et al. (2007). Similarly, due to the very low feeding rates, although Vogt et al. (2013) found nonmotile (diatom) prey in the guts of both the adults and nauplii of $O$. davisae, the clearance rate experiments performed in that study found evidence only of significant grazing on diatoms by the nauplii. Ingestion of diatoms by Oithona has occasionally been reported in the literature (Hopkins and Torres 1989; Atkinson 1995; Atienza et al. 2006). Based on this ample evidence, it is reasonable to conclude that under certain circumstances diatoms might indeed be ingested but, comparatively, at much lower rates than motile prey. 
Optimal prey for $\mathrm{O}$. davisae adults and nauplii-In most of our functional response experiments there was a clear decline on clearance rates as food availability increased. On other occasions (e.g., Fig. 2C,G), however, either because the lowest prey availabilities tested were not low enough or because the range of variation was too narrow to allow better estimations, no clear peak was evident and we had to opt for proxy values based on the maximum clearance among the observed rates. Maximum clearance rates provide the potential capability of a copepod to perceive and sweep clear a certain prey before limiting processes (e.g., handling time, gut fullness, and transit) begin to act and a satiating response develops. In the case of Oithona, which relies only on mechanical cues to detect prey (Svensen and Kiørboe 2000), overly small prey might not produce a hydrodynamic signal strong enough to be detected and might be less efficiently handled. As prey size increases, due to the general relationship between an organism's size and its swimming velocity (Hansen et al. 1997), a positive relationship between prey size and maximum clearance rate would be expected. Above a certain threshold value, however, either the inability to handle overly large prey and/or a better escape ability of the larger prey may cause a dome-shaped relationship similar to the one found in this study. In our experiments, $O$. davisae adult females exhibited the highest clearance rates when feeding on the ciliate S. sulcatum (Fig. 3). The high clearance rates shown for the ciliate compared to other prey could be a result of the greater swimming speeds of ciliates than of phytoplankton. The reported swimming speeds of the ciliate $S$. sulcatum in the literature $\left(0.59 \mathrm{~mm} \mathrm{~s}^{-1}\right.$; Kiørboe et al. 2009) are higher than the values for the two large dinoflagellates used in our experiments (Ox. marina: $0.37 \mathrm{~mm} \mathrm{~s}^{-1}$, Kiørboe et al. 2009; Ak. sanguinea: $0.30 \mathrm{~mm} \mathrm{~s}^{-1}$, Park et al. 2002). High clearance rates on ciliates by Oithona spp. are often reported in field studies using natural prey assemblages (Atkinson 1995; Castellani et al. 2005a; Zamora-Terol et al. 2013) and are most likely a consequence of the combination of their larger size and higher swimming speed compared with the other potential prey (Hansen et al. 1997; Jakobsen et al. 2005).

The ambush-feeding strategy shown by the nauplii and the adult females of $O$. davisae imposes constraints on the range of suitable potential prey. Maximum clearance rates for nauplii and adult females (Fig. 3) peak at smaller $(16.5 \mu \mathrm{m})$ and larger $(\sim 30 \mu \mathrm{m})$ prey sizes, respectively, as expected due to the difference in size between the nauplii and the females. The narrow range of prey sizes at which high clearance rates are observed, however, is noteworthy; the smaller and larger prey can be eaten but at substantially lower rates. Vogt et al. (2013) also observed that the range of prey sizes in the guts of the nauplii and adult females of $O$. davisae was relatively broad and similar despite the simpler and rudimentary feeding appendages of the nauplii compared with the adult females. In the latter study, however, functional response experiments were not performed, and those prey that triggered higher clearance rates could not be identified.

Deeper insights into the comparative aspects of ontogenetic changes in feeding behavior in Oithona spp. can be obtained if the prey size spectrum is scaled to the size of the predator. Figure 4A,B show the relative prey size spectrum of the nauplii and the adult females of $O$. davisae, respectively. They correspond to the same data plotted in Fig. 3 but are scaled to the predator size here. Both the nauplii and the adult females appear to have rather similar optimal relative prey sizes, defined as those prey sizes at which higher maximum clearance rates peak $(\sim 10 \%$ relative size; Fig. 4). This resemblance between the relative prey size spectra of the nauplii and of the adults is actually quite unexpected and contrasts with a previous finding for other copepods (Berggreen et al. 1988). In Fig. 4C,D, for comparison with our $O$. davisae data set, we have included data for nauplii, copepodites, and adult females of the calanoid copepod A. tonsa obtained by Berggreen et al. (1988). In contrast with our findings, $A$. tonsa showed a broadening of prey sizes and a shift towards relatively larger relative prey sizes through its ontogeny, as can also be found in other predators, such as fish larvae (Sabatés and Saiz 2000). In addition to the differences mentioned above, the optimal prey size range of the nauplii and adults of $O$. davisae (10\% relative prey size) appeared to be shifted toward much larger prey than that observed for the nauplii, copepodites, and adults of $A$. tonsa (2-6\%; Fig. 4C,D). The pattern observed in $O$. davisae is most likely a consequence of its strict ambush-feeding behavior, which requires that predation occur on prey large enough to generate hydromechanical signals above the detection threshold (either by swimming or sinking; Visser 2001). Moreover, in contrast with active swimmers, such as the nauplii and adults of A. tonsa (Saiz 1994; Titelman and Kiørboe 2003), the swimming behavior linked to the ambush strategy of $O$. davisae, which involves spending most of the time sinking with occasional jumps to regain position (Henriksen et al. 2007; Kiørboe et al. 2009), may also decrease the probability that Oithona spp. would be detected in advance by a potential prey and would favor attacks on relatively large prey (Jonsson and Tiselius 1990; Saiz and Kiørboe 1995).

Daily rations and evidence for sloppy feeding - The daily rations of $O$. davisae nauplii increased with prey size and fell within the range of variation of the few data available from previous studies of the nauplii of this species (Henriksen et al. 2007; Almeda et al. 2010a). The nauplii of $O$. davisae displayed evidence of satiation at the highest food concentrations tested except when fed Heterocapsa sp. Overall, the maximum values found in our experiments are much lower than those expected for similarly sized calanoid nauplii (which can reach daily rations up to $300 \%$ body C $\mathrm{d}^{-1}$; Saiz and Calbet 2007) and should be interpreted as a consequence of the low prey encounter rate associated with ambush feeding. In contrast, adult females showed high daily rations when fed several of the prey tested $(>150 \%$ body $\mathrm{C} \mathrm{d}^{-1}$ ), particularly those of intermediate size (Fig. 3). Applying allometric relationships (Saiz and Calbet 2007), we calculated that similarly sized calanoids $(0.3 \mu \mathrm{g}$ C) would show maximum weight-specific ingestion rates (200\% body $\mathrm{C}^{-1}$ ) comparable to those observed for $O$. davisae in our study. This result is not in agreement with most previous evidence, both from the field and the laboratory, which typically shows that the feeding rates 

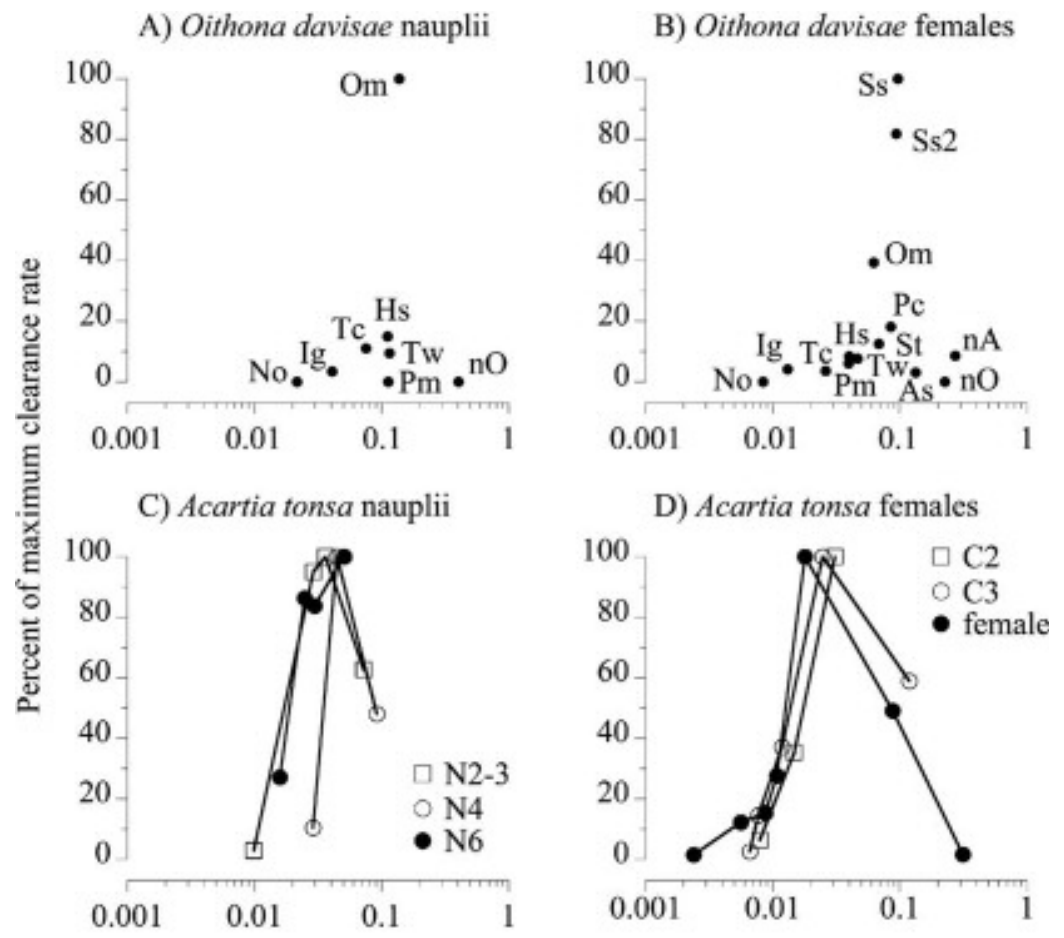

Relative prey size, ESD:prosome length

Fig. 4. Maximum clearance rate, expressed as relative value $(\%)$ among those exhibited for the different prey in each data set, as a function of the prey : predator size ratio. (A) Nauplii and (B) adult females of Oithona davisae from the current study. (C) Nauplii and (D) copepodite and adult stages of the calanoid copepod Acartia tonsa from Berggreen et al. (1988). No, Nannochloropsis oculata; Ig, Isochrysis galbana; Tc, Tetraselmis chuii; Hs, Heterocapsa sp.; Pm, Prorocentrum minimum; Tw, Thalassiosira weissflogii; Om, Oxyrrhis marina; St, Scrippsiella trochoidea from the Fmax experiments; Pc, Prorocentrum micans from the Fmax experiments; Ss, Strombidium sulcatum; Ss2, Strombidium sulcatum from the Fmax experiments; As, Akashiwo sanguinea; nO, Oithona davisae nauplii as prey; nA, Acartia grani nauplii as prey.

of Oithona are much lower than those of calanoids (Saiz and Calbet 2007). The maximum daily rations found in our study are also higher than those that can be derived from maximum egg production rates reported in seasonal field studies (maximum daily rations needed assuming 30\% gross growth efficiency: $O$. davisae in an eutrophic inlet of the Inland Sea of Japan: $98 \%$ body $\mathrm{C} \mathrm{d}^{-1}$ at $18^{\circ} \mathrm{C}$, Uye and Sano 1998; Oithona sp. in mangroves in Australia: 73\% body $\mathrm{C} \mathrm{d}^{-1}$ at $29^{\circ} \mathrm{C}$, McKinnon and Klumpp 1998; O. nana in waters off Argentina: $37 \%$ body $\mathrm{C} \mathrm{d}^{-1}$ at $20^{\circ} \mathrm{C}$, Temperoni et al. 2010; O. similis in the North Sea: $40 \%$ body $\mathrm{C} \mathrm{d}^{-1}$ at $14.7^{\circ} \mathrm{C}$, Drif et al. 2010).

One possible explanation for the high maximum daily rations found could be that at satiation levels, the copepods might be feeding primarily on a subrange of small-sized individuals within the prey population. As we did not contemplate changes in prey size in our experiments, we might have overestimated feeding rates in our calculations if such selection for a small size subrange had occurred. We have conducted a test of this hypothesis with Ox. marina as prey (at 1000 and 1500 cells $\mathrm{mL}^{-1}$, with ingestion rates of, respectively, $1002 \pm 91.0$ standard error $[\mathrm{SE}]$ and $862 \pm$ 136.3 SE cells ind..$^{-1} \mathrm{~d}^{-1}$ ) and observed no difference in the size spectra at the end of the incubation between control (no copepods) and experimental (with added copepods) bottles (data not shown). Even ignoring this result, in the case where the copepods had been feeding selectively on a subrange of prey sizes, either below (when the offered prey was relatively too large) or above (when the offered prey was relatively too small) the population median, the expected variation in daily rations with respect to the assumption that the copepods were feeding on the whole prey population would be on the order of $\pm 30 \%$. Even if this correction is applied, however, several of our maximum daily rations for $O$. davisae still appear too high in view of the literature values discussed above.

We suggest that our extreme maximum ingestion rates, obtained from prey removal experiments, do not fully represent the actual amount of prey biomass ingested. Figure 5A shows pictures at the same scale of an adult female of $O$. davisae and all the prey offered in the experiments, and Fig. 5B shows a scanning electron microscope picture of the mouth of an adult female of $O$. davisae. As shown in Fig. 5, the dimensions of the mouth of the adult female $O$. davisae $(\sim 10 \mu \mathrm{m} \times 20 \mu \mathrm{m})$ are similar to or even smaller than the size of the prey that resulted in daily rations $>150 \%$ body $\mathrm{C} \mathrm{d}^{-1}$. The physical limitations involved in swallowing prey of similar (or larger) size than the mouth itself would involve the 
A

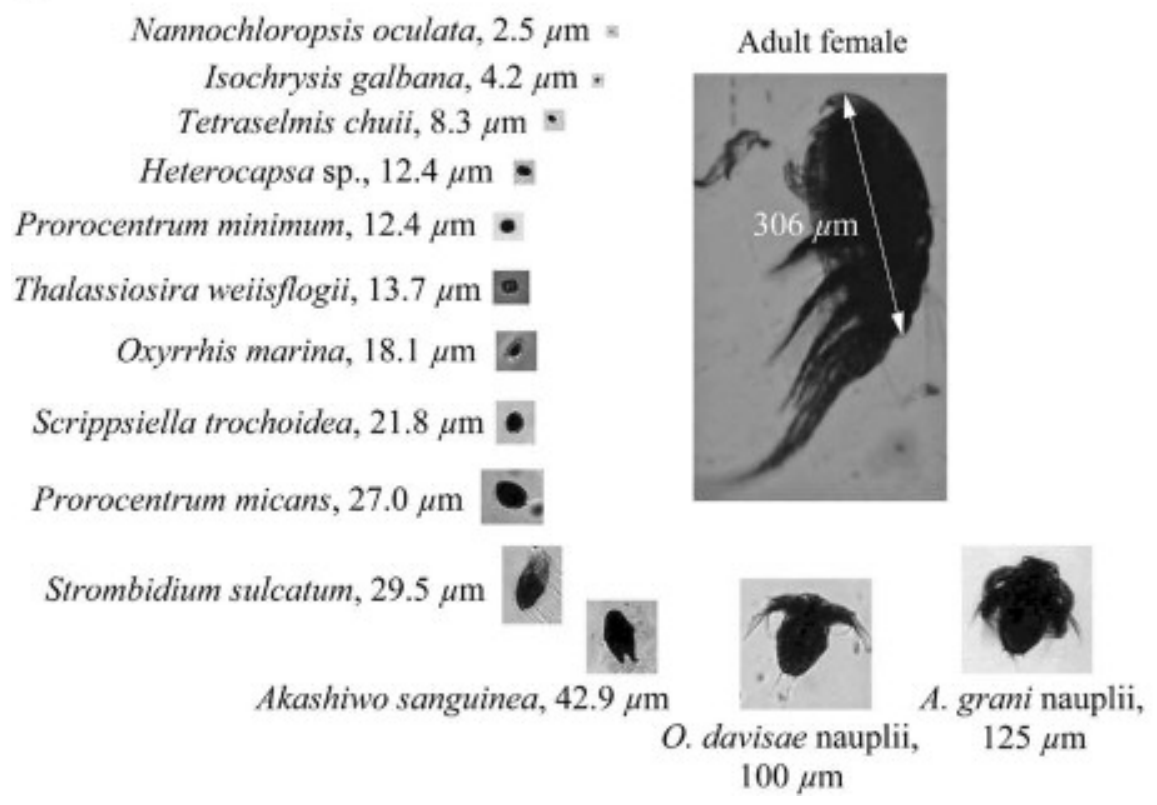

B

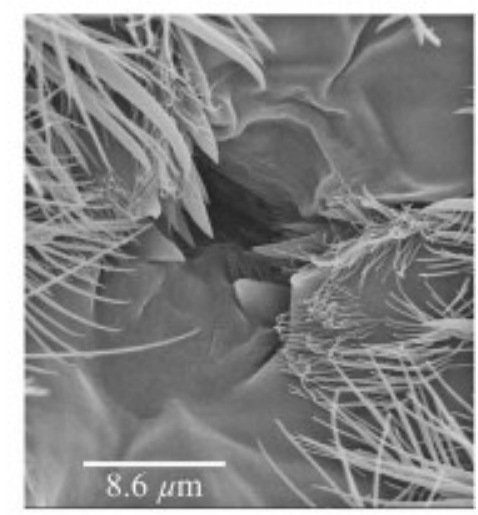

Fig. 5. (A) Microscope images of adult female Oithona davisae and all the prey offered in the feeding incubations. Images are scaled to the same magnification. (B) Detail of the mouth of an adult female of Oithona davisae viewed with the scanning electron microscope $(3500 \times)$.

breakage and partial ingestion of the prey, resulting in an actual consumption of organic matter much lower than that estimated from the counts in the incubation bottles. This evidence of sloppy feeding in $O$. davisae is, as far as we know, the first case reported for Oithona, and would be in agreement with the low gross growth efficiencies (16\%) for adult female $O$. davisae reported by Zamora-Terol and Saiz (2013) when feeding on $O x$. marina; previous quantitative assessments of sloppy feeding in copepods are limited to a few species of calanoids (Strom et al. 1997; Møller and Nielsen 2001; Møller 2007). In this regard, Møller (2007) found that the ingestion of relatively very small prey (prey: predator size ratio $\leq 1 \%$ ) resulted in not significant production of dissolved organic carbon (DOC), whereas $15-30 \%$ of the total prey carbon removal will be lost as DOC when the relative prey size is 4 $6 \%$. In the case of $O$. davisae, the relative prey sizes of those prey that resulted in very high maximum daily rations (Heterocapsa sp. and P. minimum: 4\%; Ox. marina: 6\%; S. sulcatum: $9.6 \%$ ) fall close to or above the threshold values proposed by Møller (2007) and support the presence of sloppy feeding in Oithona. It is worth noticing, however, that in those cases we did not identify any prey remains during our microscope counts, but given they were naked prey it is expectable that any remains would have degraded during the incubation.

We have shown that, in contrast to what is known for suspension-feeding calanoid copepods, $O$. davisae feeds on relatively larger prey, and both the nauplii and the adult females show similar optimal relative prey sizes. This finding appears to be a consequence of the strict ambushfeeding behavior that constrains the copepod to feed on prey large enough to trigger sufficient hydromechanical signals for detection. At high relative prey sizes, we have reported very high weight-specific ingestion rates, which are most likely unrealistic and a consequence of sloppy feeding. The presence of sloppy feeding in Oithona, which deserves further and more rigorous research, might have relevant implications for the fueling of the microbial loop in the epipelagic zone, given the high abundance and ubiquity of Oithona in the oceans, and the reported composition of their diet in the field, with high contribution of ciliates and dinoflagellates (Castellani et al. 2005a; Atienza et al. 2006; Zamora-Terol et al. 2013). Moreover, our experiments have shown that $O$. davisae is able to feed on nanoflagellates and to reach moderate maximum daily rations in the laboratory on these prey, and such a process is also expected to occur in the field. In incubations with natural assemblages, however, it is probable that the high clearance rates on ciliates and heterotrophic dinoflagellates by Oithona spp. reported in the literature may cause strong trophic cascade effects (Calbet and Saiz 2013), which may result in the underestimation of nanoflagellate consumption and total daily rations. Finally, we urge caution in the extrapolation of our results to other Oithona species, as the prey:predator size ratios would change in larger-sized conspecifics and, therefore, it is probable that the degree of sloppy feeding when feeding on large prey (e.g., ciliates and dinoflagellates) and/or the ability to feed on small nanoflagellates might differ.

\section{Acknowledgments}

We thank P. Jiménez, R. Borrat, and M. Antó for technical assistance in culture maintenance and experiments and J. M. Fortuño for scanning electron microscopy photography. We also thank the reviewers and the Editor for their comments. This research was funded by project CTM2011-23480 of the Spanish Ministry of Economy and Competitiveness. This study is a contribution 
of the Marine Zooplankton Ecology Group (2014SGR-498) at the Institut de Ciències del Mar.

\section{References}

Almeda, R., C. B. Augustin, M. Alcaraz, A. Calbet, and E. SAIz. 2010a. Feeding rates and gross growth efficiencies of larval developmental stages of Oithona davisae (Copepoda, Cyclopoida). J. Exp. Mar. Biol. Ecol. 387: 24-35, doi:10.1016/ j.jembe.2010.03.002

, A. Calbet, M. Alcaraz, L. Yebra, and E. Saiz. $2010 b$. Effects of temperature and food concentration on the survival, development and growth rates of naupliar stages of Oithona davisae (Copepoda, Cyclopoida). Mar. Ecol. Prog. Ser. 410: 97-109, doi:10.3354/meps08625

Atienza, D., A. Calbet, E. Saiz, M. Alcaraz, and I. Trepat. 2006. Trophic impact, metabolism, and biogeochemical role of the marine cladoceran Penilia avirostris and the codominant copepod Oithona nana in NW Mediterranean coastal waters. Mar. Biol. 150: 221-235, doi:10.1007/s00227006-0351-z

Atkinson, A. 1995. Omnivory and feeding selectivity in five copepod species during spring in the Bellingshausen Sea, Antarctica. ICES J. Mar. Sci. 52: 385-396, doi:10.1016/1054-3139(95) 80054-9

Berggreen, U., B. Hansen, And T. Kiørboe. 1988. Food size spectra, ingestion and growth of the copepod Acartia tonsa during development: Implications for determination of copepod production. Mar. Biol. 99: 341-352, doi:10.1007/BF02112126

Broglio, E., E. Saiz, A. Calbet, I. Trepat, and M. Alcaraz. 2004. Trophic impact and prey selection by crustacean zooplankton on the microbial communities of an oligotrophic coastal area (NW Mediterranean Sea). Aquat. Microb. Ecol. 35: $65-78$, doi: $10.3354 / \mathrm{ame} 035065$

Calbet, A., M. R. Landry, and R. D. Scheinberg. 2000. Copepod grazing in a subtropical bay: Species-specific responses to a midsummer increase in nanoplankton standing stock. Mar. Ecol. Prog. Ser. 193: 75-84, doi:10.3354/meps 193075

- , AND E. SAIz. 2013. Effects of trophic cascades in dilution grazing experiments: From artificial saturated feeding responses to positive slopes. J. Plankton Res. 35: 1183-1191, doi:10.1093/plankt/fbt067

Castellani, C., X. Irigoien, R. P. Harris, and R. S. Lampitt. 2005a. Feeding and egg production of Oithona similis in the North Atlantic. Mar. Ecol. Prog. Ser. 288: 173-182, doi:10. 3354/meps 288173

D. J. Mayor, R. P. Harris, and D. Wilson. 2008. Feeding of Calanus finmarchicus and Oithona similis on the microplankton assemblage in the Irminger Sea, North Atlantic. J. Plankton Res. 30: 1095-1116, doi:10.1093/plankt/ fbn074

- C. Robinson, T. Smith, and R. S. Lampitt. $2005 b$. Temperature affects respiration rate of Oithona similis. Mar. Ecol. Prog. Ser. 285: 129-135, doi:10.3354/meps285129

Drif, K., A. G. Hirst, and S. Hay. 2010. Seasonal abundance and egg production rates of Oithona similis and Pseudocalanus elongatus in the northern North Sea: A first comparison of egg-ratio and incubation methods. Mar. Ecol. Prog. Ser. 415: 159-175, doi:10.3354/meps08748

Drits, A., And T. Semenova. 1984. Experimental investigations of the feeding of Oithona similis Claus. Oceanology 24: 755-759.

Frost, B. W. 1972. Effects of size and concentration of food particles on the feeding behavior of the marine planktonic copepods Calanus pacificus. Limnol. Oceanogr. 17: 805-815, doi:10.4319/lo.1972.17.6.0805
Gallienne, C. P., And D. B. Robins. 2001. Is Oithona the most important copepod in the world's oceans? J. Plankton Res. 23: 1421-1432, doi:10.1093/plankt/23.12.1421

Hansen, P. J., P. K. Buornsen, and B. W. Hansen. 1997. Zooplankton grazing and growth: Scaling within the $2-2,000-\mu \mathrm{m}$ body size range. Limnol. Oceanogr. 42: 687-704, doi:10.4319/1o.1997.42.4. 0687

Henriksen, C. I., E. Saiz, A. Calbet, and B. W. Hansen. 2007. Feeding activity and swimming patterns of Acartia grani and Oithona davisae nauplii in the presence of motile and nonmotile prey. Mar. Ecol. Prog. Ser. 331: 119-129, doi:10.3354/ meps331119

Hopkins, T. L., And J. J. Torres. 1989. Midwater food web in the vicinity of a marginal ice zone in the western Weddell Sea. Deep-Sea Res. 36: 543-560.

Jakobsen, H. H., E. Halvorsen, B. W. Hansen, and A. W. VISSER. 2005. Effects of prey motility and concentration on feeding in Acartia tonsa and Temora longicornis: The importance of feeding modes. J. Plankton Res. 27: 775-785, doi:10.1093/plankt/fbi051

Jonsson, P. R., AND P. Tiselius. 1990. Feeding behaviour, prey detection and capture efficiency of the copepod Acartia tonsa feeding on planktonic ciliates. Mar. Ecol. Prog. Ser. 60: 35-44, doi:10.3354/meps060035

Kiørboe, T., A. Andersen, V. J. Langlois, H. H. Jakobsen, and T. Bohr. 2009. Mechanisms and feasibility of prey capture in ambush-feeding zooplankton. Proc. Natl. Acad. Sci. USA 106: 12394-12399, doi:10.1073/pnas.0903350106

, E. Saiz, and M. Vittasalo. 1996. Prey switching behaviour in the planktonic copepod Acartia tonsa. Mar. Ecol. Prog. Ser. 143: 65-75, doi:10.3354/meps143065

— AND A. W. VisSER. 1999. Predator and prey perception in copepods due to hydromechanical signals. Mar. Ecol. Prog. Ser. 179: 81-95, doi: $10.3354 /$ meps 179081

LAMPITT, R. S. 1978. Carnivorous feeding by a small marine copepod. Limnol. Oceanogr. 23: 1228-1231, doi:10.4319/lo.1978.23.6.1228

_, AND J. C. Gamble. 1982. Diet and respiration of the small planktonic marine copepod Oithona nana. Mar. Biol. 66: 185-190, doi:10.1007/BF00397192

McKinnon, A. D., And D. W. Klumpr. 1998. Mangrove zooplankton of North Queensland, Australia II. Copepod egg production and diet. Hydrobiologia 362: 145-160, doi:10.1023/A:1003138718716

Menden-Deuer, S., E. J. Lessard, and J. Satterberg. 2001. Effect of preservation on dinoflagellate and diatom cell volume and consequences for carbon biomass predictions. Mar. Ecol. Prog. Ser. 222: 41-50, doi:10.3354/meps 222041

Møller, E. F. 2005. Sloppy feeding in marine copepods: Preysize-dependent production of dissolved organic carbon. J. Plankton Res. 27: 27-35, doi:10.1093/plankt/fbh147

- 2007. Production of dissolved organic carbon by sloppy feeding in the copepods Acartia tonsa, Centropages typicus, and Temora longicornis. Limnol. Oceanogr. 52: 79-84, doi:10.4319/ 10.2007.52.1.0079

— AND T. G. Nielsen. 2001. Production of bacterial substrate by marine copepods: Effect of phytoplankton biomass and cell size. J. Plankton Res. 23: 527-536, doi:10.1093/plankt/23.5.527

Nakamura, Y., And J. T. Turner. 1997. Predation and respiration by the small cyclopoid copepod Oithona similis: How important is feeding on ciliates and heterotrophic flagellates? J. Plankton Res. 19: 1275-1288, doi:10.1093/plankt/19.9.1275

Nejstgaard, J. C., L. J. Naustvoll, and A. Sazhin. 2001. Correcting for underestimation of microzooplankton grazing in bottle incubation experiments with mesozooplankton. Mar. Ecol. Prog. Ser. 221: 59-75, doi:10.3354/meps221059 
Nielsen, T. G., and M. Sabatini. 1996. Role of cyclopoid copepods Oithona spp. in North Sea plankton communities. Mar. Ecol. Prog. Ser. 139: 79-93, doi:10.3354/meps 139079

PAfFenhöfer, G. A. 1993. On the ecology of marine cyclopoid copepods (Crustacea, Copepoda). J. Plankton Res. 15: 37-55, doi:10.1093/plankt/15.1.37

Paffenhöfer, G.-A., And M. G. Mazzocchi. 2002. On some aspects of the behaviour of Oithona plumifera (Copepoda: Cyclopoida). J. Plankton Res. 24: 129-135, doi:10.1093/plankt/ 24.2.129

Park, M. G., S. K. Cooney, J. S. Kim, and D. W. Coats. 2002. Effects of parasitism on diel vertical migration, phototaxis/ geotaxis, and swimming speed of the bloom-forming dinoflagellate Akashiwo sanguinea. Aquat. Microb. Ecol. 29: 11-18, doi:10.3354/ame029011

Putt, M., and D. K. Stoecker. 1989. An experimentally determined carbon: volume ratio for marine "oligotrichous" ciliates from estuarine and coastal waters. Limnol. Oceanogr. 34: 1097-1103, doi:10.4319/1o.1989.34.6.1097

Reigstad, M., C. W. Riser, and C. Svensen. 2005. Fate of copepod faecal pellets and the role of Oithona spp. Mar. Ecol. Prog. Ser. 304: 265-270, doi:10.3354/meps304265

Roff, J. C., J. T. Turner, M. K. Webber, and R. R. Hopcroft. 1995. Bacterivory by tropical copepod nauplii: Extent and possible significance. Aquat. Microb. Ecol. 9: 165-175, doi:10. 3354/ame009165

Sabatés, A., And E. SAIz. 2000. Intra- and interspecific variability in prey size and niche breadth of myctophiform fish larvae. Mar. Ecol. Prog. Ser. 201: 261-271, doi:10.3354/meps201261

SAIZ, E. 1994. Observations of the free-swimming behavior of Acartia tonsa: Effects of food concentration and turbulent water motion. Limnol. Oceanogr. 39: 1566-1578, doi:10.4319/ 10.1994.39.7.1566

—, AND A. CALBET. 2007. Scaling of feeding in marine calanoid copepods. Limnol. Oceanogr. 52: 668-675, doi:10.4319/lo.2007. 52.2.0668

- AND 2011. Copepod feeding in the ocean: Scaling patterns, composition of their diet and the bias of estimates due to microzooplankton grazing during incubations. Hydrobiologia 666: 181-196, doi:10.1007/s10750-010-0421-6

- - , AND E. Broglio. 2003. Effects of small-scale turbulence on copepods: The case of Oithona davisae. Limnol. Oceanogr. 48: 1304-1311, doi:10.4319/1o.2003.48.3.1304

_, AND T. KiørвoE. 1995. Predatory and suspension-feeding of the copepod Acartia tonsa in turbulent environments. Mar. Ecol. Prog. Ser. 122: 147-158, doi:10.3354/meps122147

Strickler, J. R. 1985. Feeding currents in calanoid copepods: Two new hypotheses, p. 459-485. In M. S. Laverack [ed.], Physiological adaptations of marine animals. Symp. Soc. Exp. Biol., 39. The Company of Biologists Limited, The University of Cambridge.
Strom, S. L., R. Benner, S. Ziegler, and M. J. Dagg. 1997. Planktonic grazers are a potentially important source of marine dissolved organic carbon. Limnol. Oceanogr. 42: 1364-1374, doi:10.4319/1o.1997.42.6.1364

Svensen, C., And T. Kiørboe. 2000. Remote prey detection in Oithona similis: Hydromechanical versus chemical cues. J. Plankton Res. 22: 1155-1166, doi:10.1093/plankt/22.6.1155

Temperoni, B., M. D. Viñas, N. Diovisalvi, and R. Negri. 2010. Seasonal production of Oithona nana Giesbrecht, 1893 (Copepoda: Cyclopoida) in temperate coastal waters off Argentina. J. Plankton Res. 33: 729-740, doi:10.1093/ plankt/fbq141

Titelman, J. 2001. Swimming and escape behavior of copepod nauplii: Implications for predator-prey interactions among copepods. Mar. Ecol. Prog. Ser. 213: 203-213, doi:10.3354/ meps 213203

—, AND T. KiøRBoe. 2003. Motility of copepod nauplii and implications for food encounter. Mar. Ecol. Prog. Ser. 247: 123-135, doi:10.3354/meps247123

Uchima, M., and R. Hirano. 1986. Food of Oithona davisae (Copepoda: Cyclopoida) and the effect of food concentration at first feeding on the larval growth. Bull. Planktonic Soc. Jpn. 33: 21-28.

Uye, S.-I., AND K. SANO. 1998. Seasonal variations in biomass, growth rate and production rate of the small cyclopoid copepod Oithona davisae in a temperate eutrophic inlet. Mar. Ecol. Prog. Ser. 163: 37-44, doi:10.3354/meps163037

Visser, A. W. 2001. Hydromechanical signals in the plankton. Mar. Ecol. Prog. Ser. 222: 1-24, doi:10.3354/meps222001

Vogt, R. A., T. R. Ignoffo, L. J. Sullivan, J. Herndon, J. H. Stillman, AND W. J. Kimmerer. 2013. Feeding capabilities and limitations in the nauplii of two pelagic estuarine copepods, Pseudodiaptomus marinus and Oithona davisae. Limnol. Oceanogr. 58: 2145-2157, doi:10.4319/1o.2013.58. 6.2145

Zamora-Terol, S., T. G. Nielsen, and E. Saiz. 2013. Plankton community structure and role of Oithona similis on the western coast of Greenland during the winter-spring transition. Mar. Ecol. Prog. Ser. 483: 85-102, doi:10.3354/ meps 10288

— AND E. SAIz. 2013. Effects of food concentration on egg production and feeding rates of the cyclopoid copepod Oithona davisae. Limnol. Oceanogr. 58: 376-387, doi:10.4319/lo.2013. 58.1.0376

Associate editor: Robert W. Sterner

Received: 08 April 2014 Accepted: 02 September 2014 Amended: 19 August 2014 